\title{
Teachers' readiness to use ICT in the conditions of inclusive education
}

\author{
Aliya Oralbekova ${ }^{1, *}$, Saule Begalieva ${ }^{3}$, Akmaral Ortaeva $^{1}$, Akmaral Magauova $^{2}$, and \\ Madina Suleimen ${ }^{2}$ \\ ${ }^{1}$ South Kazakhstan State Pedagogical University, A.Baitursynov st., 13, Shymkent, Kazakhstan \\ ${ }^{2}$ Al-Farabi Kazakh National University, al-Farabi ave., 71, Almaty, Kazakhstan \\ ${ }^{3}$ Abai Kazakh National Pedagogical University, Dostyk ave., 13, Almaty, Kazakhstan
}

\begin{abstract}
This article focuses on the formation of future pre-school teachers' readiness to use the information and communication technologies (ICT) in the conditions of inclusive education and their training at universities. Authors justify the necessary of formation students' capability in modern ICT area. In the article, using of the ICT in the conditions of inclusive education for the eldest pre-school children is identified based on the theoretical analysis of scientific literature. The article shows survey results about identifying the main reasons of the obstacles of implemention ICTs in the educational process of pre-school organizations in the Republic of Kazakhstan. The structural and content model "Formation students' professional competence of ICT using in inclusive environment" was presented. This article was written under project number AP0805340 "The development of a computer-educational program "Alemdy Tanu" for the adaptation of pre-school children to school in the conditions of inclusive education" supported by National Scientific Council.
\end{abstract}

\section{Introduction}

In Kazakhstan, there are more than 150 thousand children with disabilities. The main task of government is giving them all-around support, including access to quality education. The practice of general education with the inclusion of special children in society is the best way to solve this problem [1].

According to Conceptual approaches to the development of inclusive education in the Republic of Kazakhstan [2], and State Program for the Development of Education and Science of the Republic of Kazakhstan for 2020 - 2025 [3] the development of inclusive education in the Republic of Kazakhstan is the most important direction.

An accessible information environment is a criteria of inclusive society. The American scientist and philosopher I.V. Robert wrote about information technologies (IT) as a set of extraction, collection, systematization and information processing activities for the effective management of social, political, economic and technical processes in the state [4]. I. SirajBlatchford believes that information and computer competence allow to get competitive advantages in the education market [5].

\footnotetext{
* Corresponding author: qbabou@gmail.com
} 
The using ICT in inclusive education to develop of all aspects of child's speech and thinking, help to solve tasks which children have not learned or have not understant enough, to realize their potential capabilities that can not be occur in traditional conditions, to implement the self-control principle, allowing children feel free, to actively and independently control the game, it strengthens faith in their own strength unlike other games and activities, developing a verbal activity in three ways: as a communication tool; a computer as an user partner; three-way communication of the classroom: students, a teacher and a computer. As many authors note using computer games allows to optimize the pedagogical process, individualize the teaching of children with developmental disorders and increase the efficiency of any activity [6].

The joint coordinated work of the motor, auditory and visual analyzers in doing computer program tasks activate the child's compensatory mechanisms. In this regard, the use of computer gaming technologies is becoming especially expedient, interesting because all informations are presented in an attractive format. It not only speeds up the memorization of the content, but also makes it meaningful and long-term [7].

According to work of A. Mamutovic, M. Markovic and Z. Petrovic Stanisavljevic teachers view computer games as helpful educational tool, stimulating pre-school children learning and affecting positively on logical thinking, also it increases intellectual developing and cognitive abilities [8].

It should be noted that the using computer technologies in inclusive educational environment needs teacher's constantly competence development. During the pandemic the authors note difficulties according to: theachers' digital skills training; digital divide between teachers according to their gender, age and type of school; weak technological competence that affect to distance learning badly [9].

Local and foreigh educators believe that pre-school teachers should train to use computerbased educational programs immediately after the graduation [10]. A. Tuncay, A. Kizilaslan noted that future pre-school teachers need more possibilities and practice of working with students with SEN during their school practice. Also, they showed that pre-school teachers should have a practice and self-confidence along with knowledge about law and policy about inclusion [11].

The studies have shown that the future pre-school teachers' readiness to use ICT in the conditions of inclusive education problem is relevant and necessary for lifelong educational system's theory and practice.

The study aims to identify problems of future pre-school teachers' readiness to use ICT in the conditions of inclusive education and creation a structural and content model.

\section{Materials and methods}

We relied on a combination of such methodological approaches as systems and structural, personal and activity approaches to conduct a holistic, objective and productive scientific research. Methodological bases for the study are presented by concepts, that reveal the essence of using ICTs in the educational process; systems and structural, personal and activity approaches; theories of personality development; principle of unity of education and personal development and others.

Different methods were used in this study, including document analysis, questionnaire survey.

A survey was taken among South Kazakstan State Pedagogical University students. All participants $(\mathrm{N}=100)$ were future pre-school teachers (last course students). This survey examined students' beliefs, knowledge, practice about the use of ICT in the pre-school organizations and the main causes of challenges of using ICTs in the learning process. The questionnaire was designed to elicit the following informations: students' knowledge and 
practice about the using ICT in the conditions of inclusive education, their beliefs about the integration of ICT, problems and causes of the lack of ICT integration, students training to use ICT in the learning process at universities. Also, we analysed early childhood curriculums of the 12 pre-school organizations in the city Shymkent, Kazakhstan to identify the main causes of lack of the using ICT in the learning process.

\section{Results}

The process of integration new informatic methods and modern information technologies to educational process is conducted in accordance with informatisation strategies of education. All educational organizations are equipped with computer technology. An obstacle for informatization is a moral outmoding of learning classes (about $68 \%$ of whole class) [12].

Document analysis. It does not apply to use technical and software tools in the educational process. During the informational documents analyzing 12 pre-school organizations in Shymkent, Kazakhstan (two of them is inclusive pre-school organizations, selected by Simple random sampling), we noticed that the majority of them work with traditional program, and have not computer-based programs. Subjectivity of current teachers seriously narrows down the amout of informational knowledge to develop children as an active informated person along with changing times. In many programs of learning, it does not paid more attention on the using tools, means, algoritims of informational resources processing by children with SEN.

The main causes of under-using ICTs in the learning process are showed in the following figure 1 .

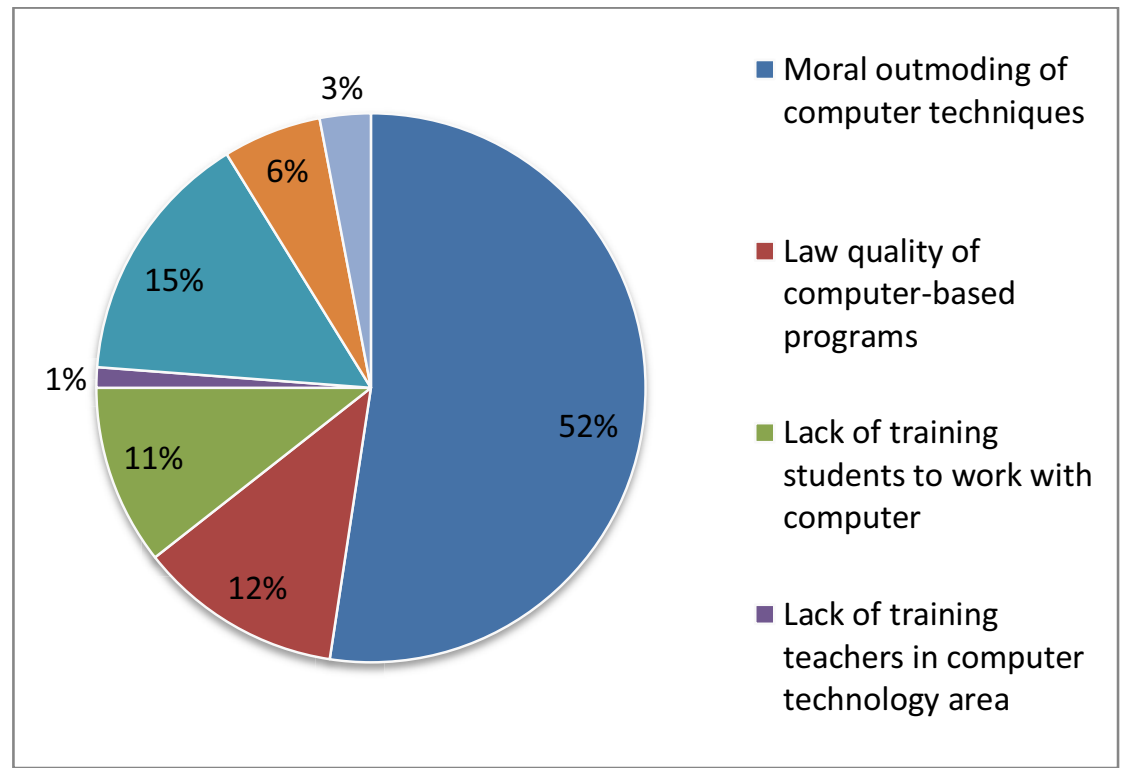

Fig. 1. The main causes of under-using ICTs in the learning process.

Survey. A hundred South Kazakstan State Pedagogical University students (future preschool teachers), whose were taken part in survey answered the questions of "ICT in education" questionnaire.

Despite that $75 \%$ of surveyed have a personal computer. The survey results show that students' informatization of the pedagogical universities hit their lowest level. The most part of surveyed (about $58 \%$ ) noted that they learned ICTs at school. 
Only $33 \%$ of them can use a computer for educational aims and have a basic knowledge about technology. Other $48 \%$ of surveyed students use a computer for Internet searching informations in education area. $12 \%$ students do not use a computer, they prefer mobile devices for learning purposes, other $7 \%$ choosed paper literatures than any kind of technology (see fig. 2).

Any student does not know how to use computer for inclusive education. While the majority of them $(75,6 \%)$ believe that integration ICTs in learning process allow to improve its value.

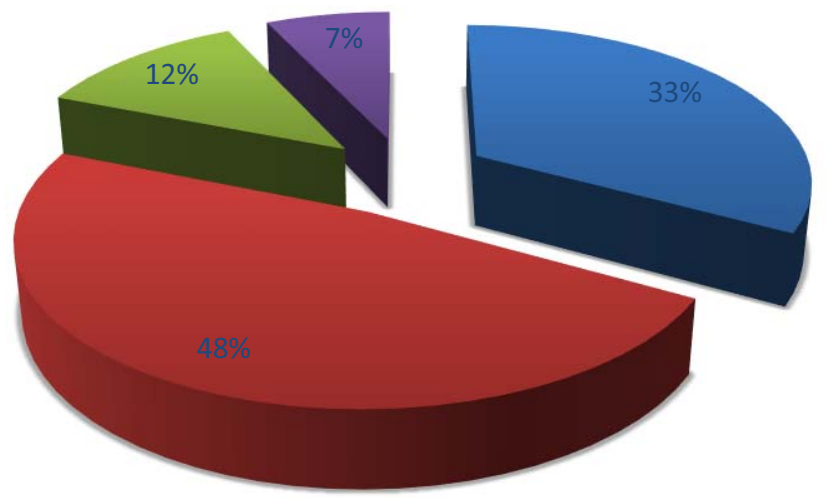

Extensive use Only for internet using

Only mobile devices using $\square$ Do not use anything

Fig. 2. The future pre-school teachers' percentages of using a computer to increase their professional skills (according to believes of surveyed students).

$81,5 \%$ surveyed noted that the educational organizations need more disciplines with ICTs. It increases chances to use tools, means and methods informational processing and providing in educational process.

$13,5 \%$ surveyed need for knowledge, skills and abilities of working with computers. Most of respondents believe that they have minimum knowledge and skills of working with computer technologies.

84 participations noted that they need knowledge, skills and abilities on information management in inclusive education. Students understand the effectiveness of using modern ICTs and computering is a necessary attributes of modern educated man.

$62 \%$ respondents agree with opinion that computer technologies in learning process have positive results in children development and their personal growth. However, almost respondents $(82 \%)$ pointed out that teachers and parents should regulary control children working process with a personal computer.

According with taken results, we can conclude that students understand an importance of using ICTs on presenting materials. The most of them believe that informational tools integration in educational process can increase the effectiveness of learning.

The future teachers understand a meaning of "imformation competence" in different ways. Because this term is wide enough. The results of questionnaire on this question are presented in fig. 3. 


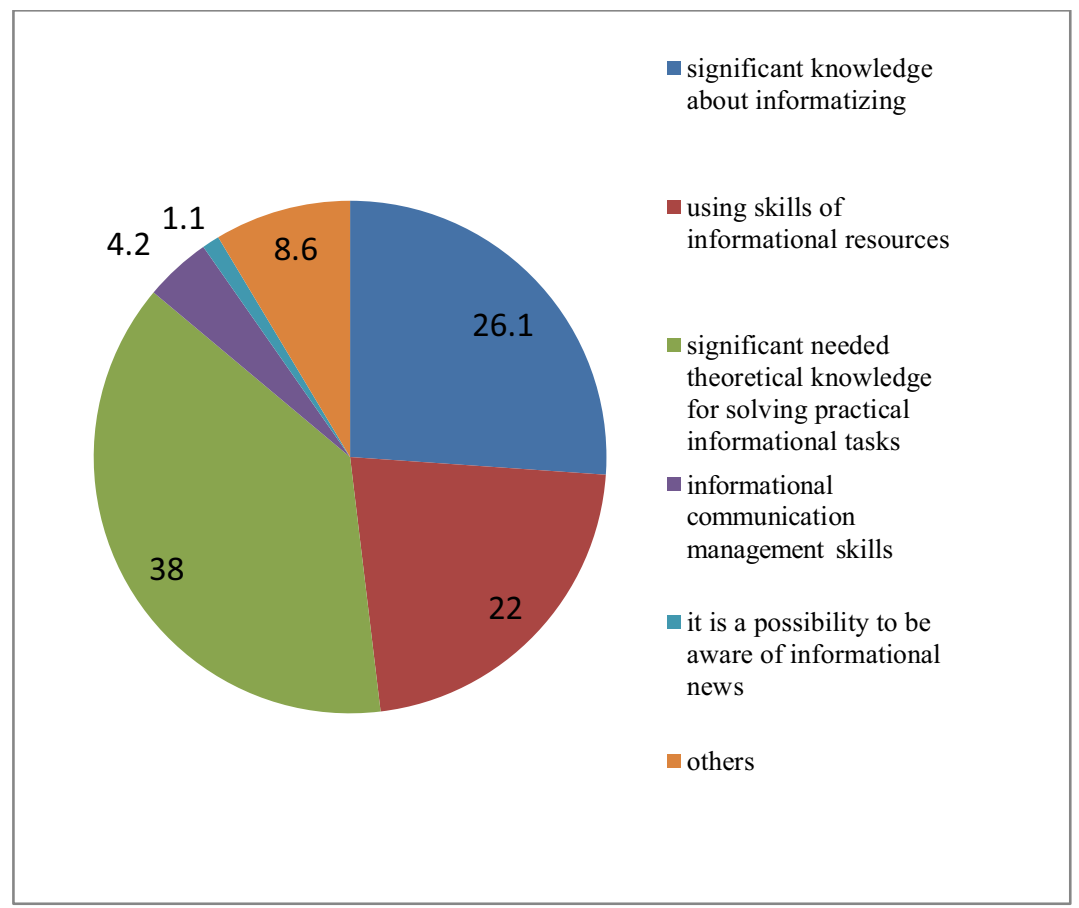

Fig. 3. The results of understanding "teachers' information competence (a competence of using ICTs in teaching activity)" by future teachers in percentage.

\section{Discussion}

Taken results prove that some future teachers do not have common understanding of "information competence" term. The majority of them have found that it is identified by a large amount of theoretical knowledge for solving practical informational tasks during their professional activities.

Informational knowledge learning should be done in stages, starting with first year of education. It allows to have enough knowledge about working with ICTs to completion of education, what will be guaranteed used in teaching process. The most disciplines potential for improving ICTs is a wide enough.

Specialists' information competence in having pedagogical education process should be designed in two main ways:

1. Scientific and pedagogical. It means future teachers should have theoretical knowledge and skills according to staff requirements of educational area. It is important to educational organizations have the same conditions with inclusive schools.

Other values of scientific and pedagogical directions are:

- explicitly addressing priority of informational and pedagogical tasks;

- formation knowledge about their scientific and pedagogical tasks, prioritizing skills in using ICTs;

- analyzing a large amount of criterias on informational tasks ranking and highlighting priorities;

- mastering of programming techniques and solving methods of standart and typical tasks;

- forming the main criterias of choose informational resources processing ways and systematization in pedagogical process. 
It means, using ICTs in learning process is an effective instrument in learning process and increasing concern for subject. Teachers need always developing and learning new knowledge, specially ICTs with special functions what help to children with SEN in developing for working activity.

2. Professional and art.

It includes the following:

- formation pedagogical enterprise, expressed through mastering ICTs and using skills in inclusive education;

- regulary developing the level of theoretical knowledge and practical skills, needing for successful realization pedagogical functions;

- quickly adapting skills to solve urgent pedagogical tasks with children with SEN;

- learning and using verify methods of information processing, analyzing and systematization;

- pedagogical aims formation skills, formulating propolsals on implementing an informational culture at school and other organizations;

- active using the scientific methods in pedagogical process aimed to identify problematic area in informational providing of inclusive learning process.

Targeted developing needs for ICT using of pedagogical universities' students is carried out in several stages. This stages are consistent with given below information competence's level (see fig. 4).

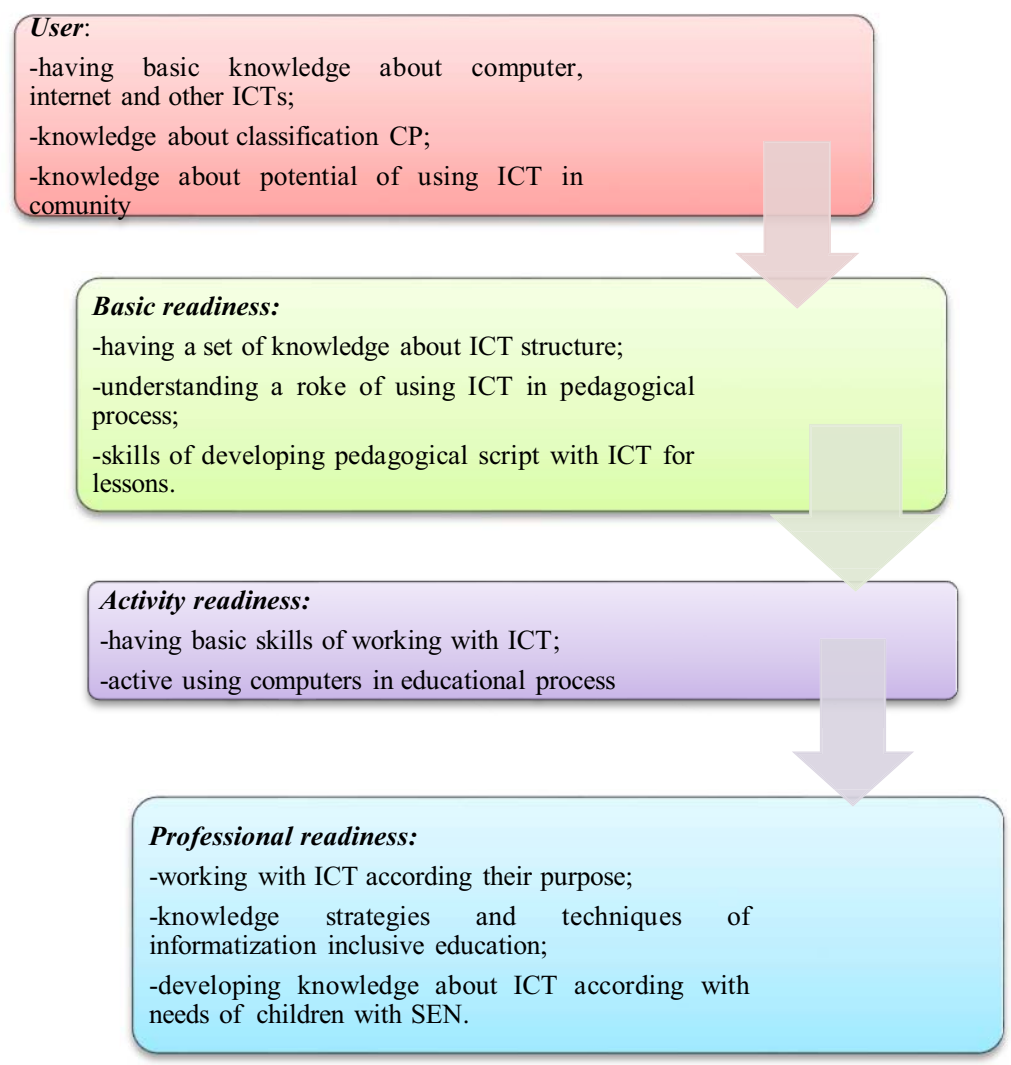

Fig. 4. Preparing stages of using ICTs in pedagogical process. 
Creating students competences of modern ICTs in educational process has spiral nature. It starts from having basic knowledge about computer and internet, also ends with free orienting on informational space and possibility in choosing optimic ICT for solving special tasks. It is an important to understand that having knowledge about computer will not escape. They are a basic of transitions to quality level of readiness to using ICT. Each level has its own pedagogical skills and abilities of working with ICT.

During an experimental work, we created a structural and content model "Formation students' professional competence of ICT using in inclusive environment" (see fig. 5).
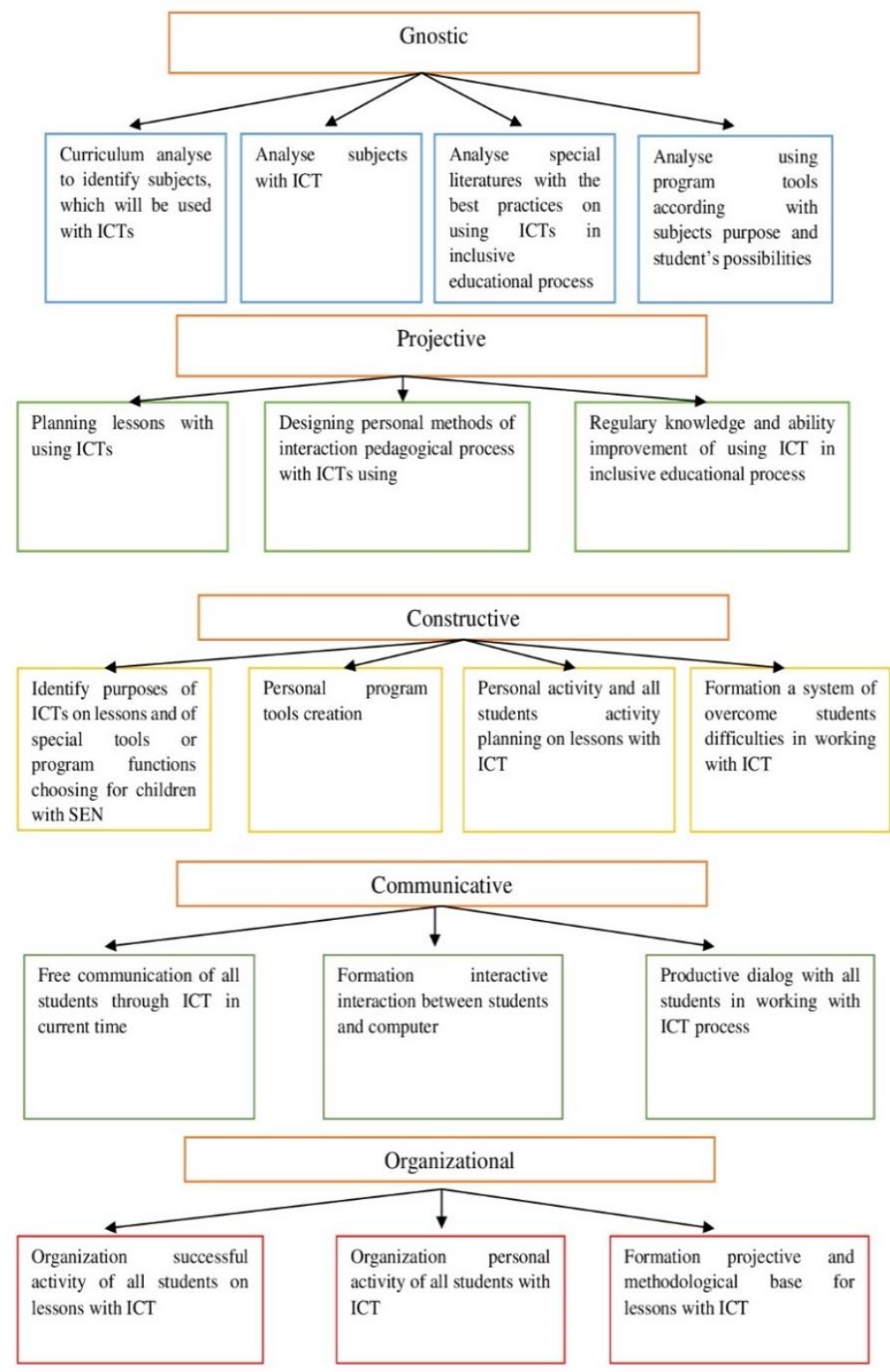

Fig. 5. A structural and content model "Formation students' professional competence of ICT using in inclusive environment".

We created aims for each professional competence level of using ICT. 
1. User aims (it is not competence yet):

- having a basic knowledge on lessons "Technology";

- overcoming psychological barrier in working with ICT;

- formation a basic practical abilities of working with a computer.

2. Basic level aims:

- improvement knowledge about ICT and their role in educational process;

- learning standart practical skills of working with a computer;

- formation a creativity of implementing ICTs in educational process.

3.Activity level aims:

- willful using ICTs in pedagogical activity;

- implementing knowledge and skills of project activity on organization lessons with ICTs, according with students ability;

4. Professional level aims:

- creative approach of using ICTs on any difficult situations for child;

- rapid transfer lessons format from standart to informatics, available to all.

So, professional competence formation in working with ICTs takes a longer period of time. Because it needs overcoming psychological barriers along with theoretical knowledge and improving practical skills. Implementing ICTs to training future teachers improves their interest of using innovative tools for a new inclusive environment.

Improving students competence about ICT using is defined by professional activity characteristics and specialization.

Based on analyzing specialist's model, we allocated four below characteristics of professional competence of using ICTs in inclusive educational environment:

- extensive theoretical knowledge about ICTs and their functions;

- formed practical skills of working with ICT;

- having installation of popularize ICT using among students;

- lack of psychological barrier of using special ICT functions for children with SEN.

A specialists training process by this model is systematic.

\section{Conclusion}

So, in our study we identified problems of future pre-school teachers' readiness to use ICT in the conditions of inclusive education in the Rebuplic of Kazakhstan, using different methods as document analysis, questionnaire survey. In our opinion, lack of readiness process to use ICT at inclusive school depends on teacher's psychological barrier, calling by lack of knowledge, skills and abilities. Furthermore, educational process does not provide common methods of systematic using ICT during educational program.

- As a result we created a structural and content model "Formation students' professional competence of ICT using in inclusive environment".

- According to pedagogical experiment results we formed following key recommendations:

- modern trends of society informatizations need a pre-school teachers training system review;

- ICT competence formation process should be implemented continuously whole period of learning activity, including pedagogical practice;

- ICT competence formation process should include theoretical knowledge, practical skills for public and special correctional schools.

This research is supported by National Scientific Council under project number AP08053408. 


\section{References}

1. Report 2016 year. According to the Ministry of Health of the Republic of Kazakhstan (Astana, 2017)

2. Order of the Minister of Education and Science of the Republic of Kazakhstan dated June 1, 2015 No. 348 "On the approval of Conceptual approaches to the development of inclusive education in the Republic of Kazakhstan". URL: https://online.zakon.kz/Document/?doc id=39711662\#pos=4;-106

3. State Program for the Development of Education and Science of the Republic of Kazakhstan for 2020 - 2025. URL: http://adilet.zan.kz/rus/docs/P1900000988

4. I.V. Robert, Theory and methods of informatization of education. Psychologicalpedagogical and technological aspects (London: Press, 2012)

5. I. Siraj-Blatchford, More than computers: Information and communication technology in the early years (London: The British Association for Early Childhood Education, 2014)

6. M.Iu. Zubkova, F.N. Baranova, En., A. Pirozhkova, A. Bubenchikova, Approaches to the future engineers foreign communicative culture formation, Humanities \& Social Sciences Reviews 7(4), 781-786 (2019)

7. Sh.M. Shaharudin, N.A. Rajak, N.W. Junus, N.A. Samat, Development and validation of early childhood care and education pre-service lecturer instrument, International Journal of Evaluation and Research in Education (IJERE) 9 (1), 188-194 (2020) DOI: 10.11591/ijere.v9i1.20415

8. A. Mamutovic, M. Markovic, S. Petrovic, Computer games and cognitive development of pre-school children, eLearning \& Software for Education 1, 48-56 (2020)

9. J. Portillo, U. Garay, E. Tejada, N. Bilbao, Self-Perception of the Digital Competence of Educators during the COVID-19 Pandemic: A Cross-Analysis of Different Educational Stages, Sustainability 12(23), 10128, 1-13 (2020) DOI: 10.3390/su122310128

10. A.K. Oralbekova, S.Z. Arzymbetova, S.B. Begalieva, M.N. Ospanbekova, G.A. Mussabekova, A.S. Dauletova, Application of information and communication technologies by the future primary school teachers in the context of inclusive education in the republic of Kazakhstan, International Journal of Environmental and Science Education 11(9), 2813-2827 (2016) DOI: 10.12973/ijese.2016.723a

11. A.A. Tuncay, A. Kizilaslan, Pre-service teachers' sentiments, attitudes and concerns about inclusive education in Turkey, European Journal of Special Needs Education (2021) DOI: 10.1080/08856257.2021.1873524

12. Education in the Republic of Kazakhstan. Report for 2016. - Astana: Ministry of Education and Science of the Republic of Kazakhstan (2017) 